\title{
Fracture union in extra articular distal tibia fracture after definitive delta frame external fixation in COVID 19 pandemic: a case report
}

\author{
Neetin P. Mahajan, Prasanna Kumar G. S., \\ Tushar Chandrakant Patil*, Pramod K. Bagimani
}

Department of Orthopaedics, Grant Government Medical College, Mumbai, Maharashtra, India

Received: 01 June 2021

Accepted: 21 June 2021

\section{*Correspondence:}

Dr. Tushar Chandrakant Patil,

E-mail: tushar6919@gmail.com

Copyright: ( ) the author(s), publisher and licensee Medip Academy. This is an open-access article distributed under the terms of the Creative Commons Attribution Non-Commercial License, which permits unrestricted non-commercial use, distribution, and reproduction in any medium, provided the original work is properly cited.

\begin{abstract}
Distal tibia fractures account for $10 \%$ of lower limb fractures. Mode of trauma also determines the fate of soft tissue recovery. In low energy fractures soft tissue show better healing whereas fractures due to high energy trauma show high chances of soft tissue complications like poor soft tissue coverage, wound infection and necrosis. We presented a 50 years old male case of extra articular left distal tibia fibula open fracture managed by delta frame external fixator with fibular $\mathrm{K}$ wiring used as a definitive management with good fracture healing and range of motion 5 months postoperative. Ankle spanning external fixation is a good modality of surgical management of extra articular compound distal tibia fractures as both temporary and definitive surgical fixation.
\end{abstract}

Keywords: Extra articular, Distal tibia, Ankle spanning, External fixation, COVID-19, Pandemic

\section{INTRODUCTION}

Distal tibia fractures account for $10 \%$ of lower limb fractures. Mode of trauma also determines the fate of soft tissue recovery. In low energy fractures soft tissue show better healing whereas fractures due to high energy trauma show high chances of soft tissue complications like poor soft tissue coverage, wound infection and necrosis. ${ }^{1}$

Distal tibia extra articular fractures have been classified by AO group in orthopaedic trauma association classification as $43 \mathrm{~A} .^{2}$

Management of distal tibia fractures is challenging, with various modalities of management like conservative casting, external fixation, intramedullary nailing, open reduction with plating and minimally invasive plate osteosynthesis. ${ }^{3}$
Non-operative conservative treatment by slabs and casts decrease quality of life of patient due to prolonged immobilization of the limb with stiffness of knee and ankle joints. ${ }^{1}$

Introduction of external fixators has brought about a revolutionary breakthrough in management of such difficult fractures which have poor soft tissue healing. Its application is easy and straight forward which decreases total surgical time with minimal soft tissue injury. ${ }^{1}$

Malgaigne introduced the technique of external fixation in 1843 and in Hoffman developed a monolateral frame in 1938. Unilateral uniplanar external fixators gave the advantage of easy and rapid application with minimal soft tissue invasion. This makes them ideal primary fixators in high energy trauma with significant soft tissue injury. ${ }^{4}$ 
External fixators also provide time for soft tissue management in compound fractures and the flexibility to adjust fracture reduction even postoperatively. ${ }^{4}$

In excessive soft tissue damage, surgical management with open reduction and plating leads to lot of soft tissue complications like wound dehisence, infection, arthrodesis or even amputation. ${ }^{5}$

\section{CASE REPORT}

50 years old male brought by coworkers to casualty with history of road traffic accident with a taxi ran over his left ankle. No history of trauma to head or chest or abdomen. No history of any comorbidities. On examination patient had local tenderness and swelling over distal third tibia with restricted range of motion of left ankle. Distal pulse was palpable with active toe movements. There was a degloving injury of dorsum of left foot of $10 \times 6 \times 0.5 \mathrm{~cm}$ as seen in Figure 1. X-ray showed extra articular distal tibia and fibula fracture as seen in Figure 2.

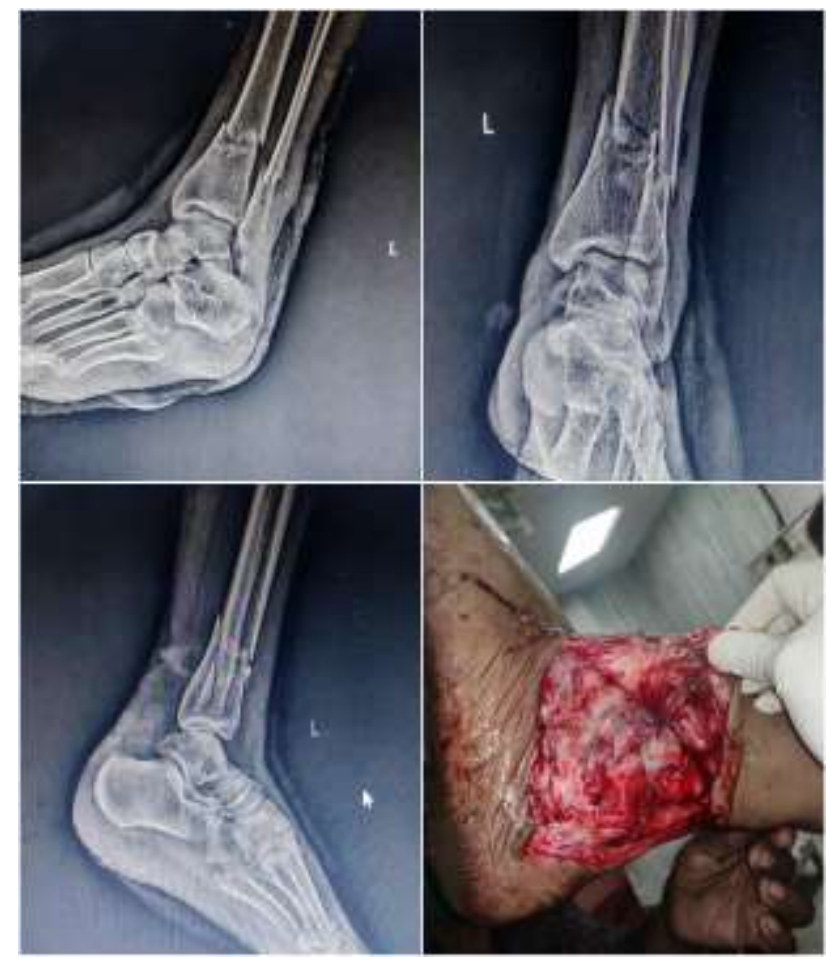

Figure 1: Preoperative left ankle $X$-ray showing extra articular distal tibia fibula fracture with open wound.

Patient was managed by ankle spanning delta frame external fixation for distal tibia without any internal fixation of fibula. Compound wound was managed with daily dressing and antibiotics according to culture sensitivity.

Patient was non-compliant for a secondary surgery and could not follow up due to strict COVID-19 lockdown.
Postoperative X-ray after 3.5 months shows good callus formation with fracture healing in Figure 3. There is good ankle range of motion with desirable functional outcome after 5 months postoperative as seen in Figure 5.

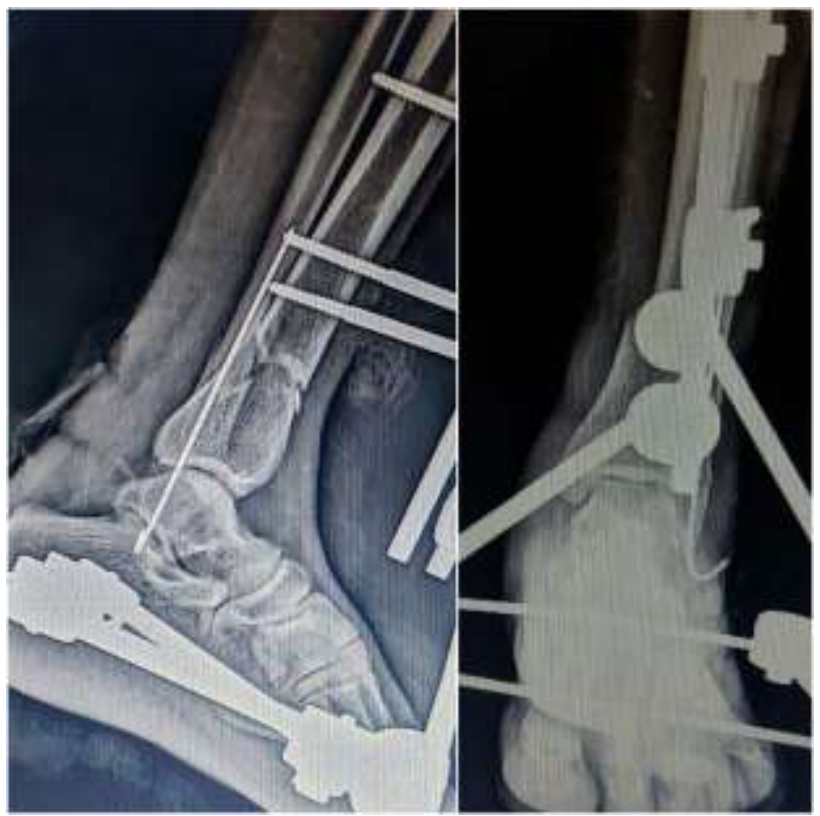

Figure 2: Immediate postoperative X-ray after delta frame external fixation and fibula $\mathrm{K}$ wiring.

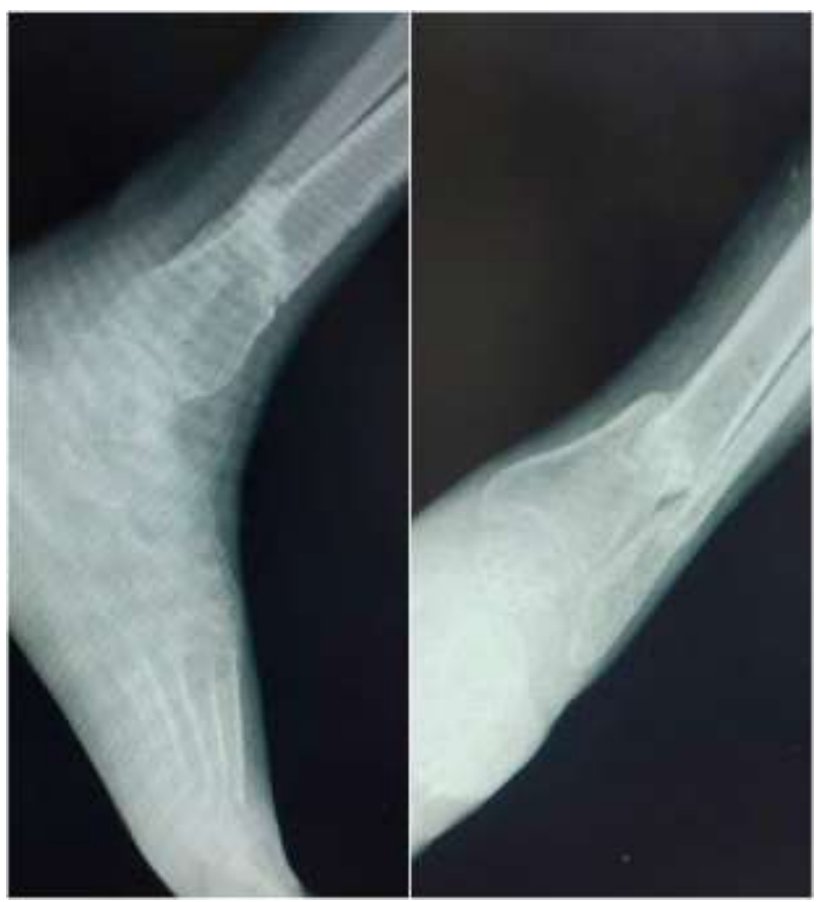

Figure 3: Left ankle X-ray showing callus formation at 3.5 months postoperative.

\section{Surgical technique}

Patient was taken on operating table in supine position. Induced under all aseptic precautions and under epidural 
plus spinal anaesthesia. Sandbag was kept under ipsilateral hip. Scrubbing, painting and draping were done. Fracture site and reduction with manual traction checked under $\mathrm{C}$ arm. First, a $3 \mathrm{~mm} \mathrm{~K}$ wire was inserted to fix the fibula. Then the proximal most pin site was marked $0.5 \mathrm{~cm}$ medial to tibial shin and small stab incision taken. Soft tissues separated with artery forceps and bone visualized. $4.5 \mathrm{~mm}$ Schanz pin drilled with sleeve, by taking purchase in bone perpendicular to the anteromedial surface of tibia and slowly making the pin perpendicular to its coronal plane. 3 more $4.5 \mathrm{~mm}$ Schanz pins were drilled similarly distal to this pin in proximal fracture fragment. Pin to rod clamps attached to these 3 proximal pins and connecting rod attached with a pin to rod clamp attached for a distal tibial pin. Distal tibial fragment pin was passed through this clamp. $5 \mathrm{~mm}$ Steinman pin was inserted in calcaneum from medial side. Delta frame was completed by inserting a 3.2 $\mathrm{mm}$ Schanz pin in first and fifth metatarsal bones. Then attaching a connecting rod to either sides. These connecting rods were then connected to connecting rod of tibial shaft. Pin to rod clamps were then tightened first of proximal 3 tibial pins. Traction was given with the help of ankle frame and alignment checked in coronal and sagittal views. Rotational alignment checked with the help of tibial shin and second metatarsal. Pin to rod clamp of distal tibial pin was tightened. Rod to rod clamps were then tightened and reduction checked and confirmed under $\mathrm{C}$ arm.

Due to strict COVID-19 lockdown, patient couldn't follow up in our hospital and came 3.5 months later with good callus formation on X-ray in Figure 3. Then external fixator and $\mathrm{K}$ wire was removed 3.5 months postoperatively and patella tendon bearing cast was given and partial weight bearing was advised for 6 weeks. After 6 weeks cast was removed and full weight bearing with help of walker started and gradually in 2 more weeks patient could walk without walker with good ankle range of motion as seen in Figure 5.

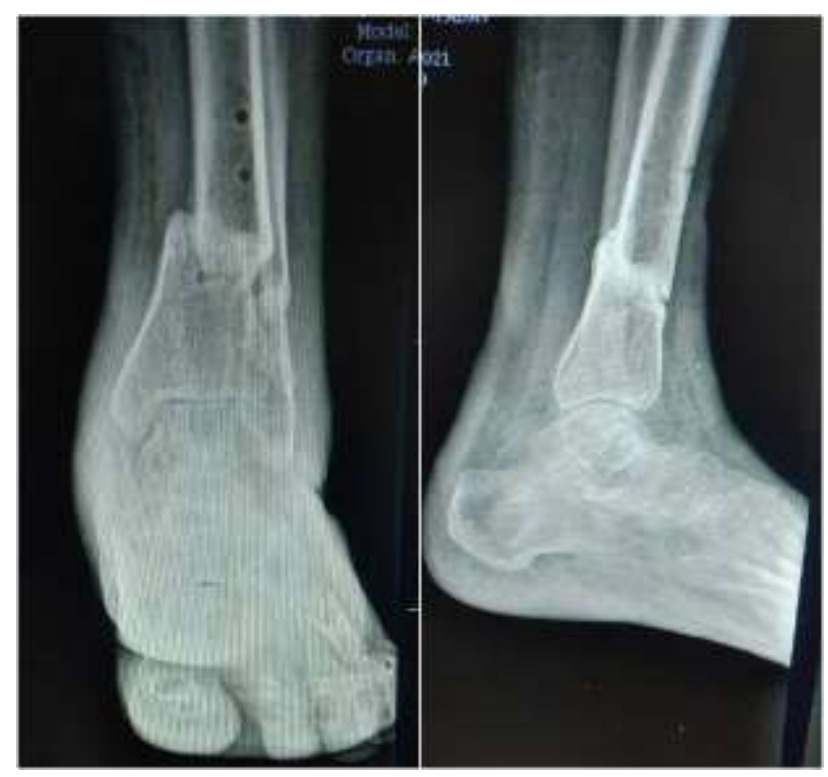

Figure 4: Left ankle X-ray at 5 months postoperative.

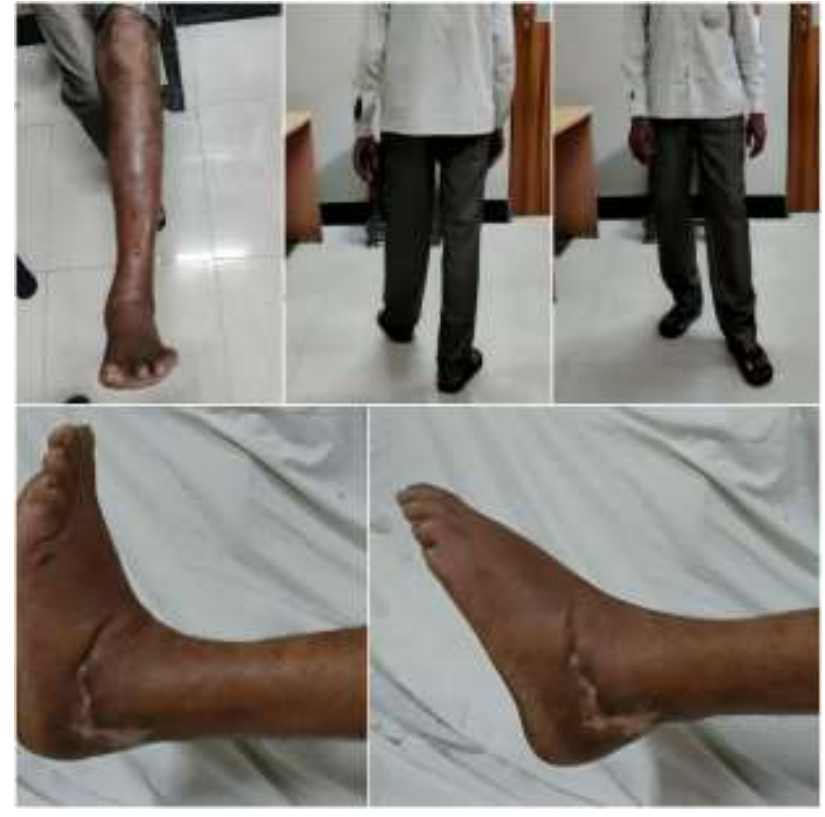

Figure 5: Patient was able to walk full weight bearing with good ankle range of motion at 5 months postoperative.

\section{DISCUSSION}

Distal tibia fractures are difficult to manage due to very poor soft tissue coverage causing increased swelling and edema, venous stasis, wound contamination, metaphyseal impaction, articular comminution and non-union. ${ }^{6}$

Mechanism and energy of trauma, degree of soft tissue involvement, fracture morphology, neurovascular injury and fracture location have been implicated as prognostic factors for fracture healing in this region. ${ }^{2}$

Stability of fixation, type of fixation, operative time and periosteal stripping during open reduction also affect fracture healing. ${ }^{2}$

Preliminary temporary fixation of distal tibia fractures with external fixators prior to definitive fixation have remarkably decreased the incidence of soft tissue infections and wound dehisence after open reduction with plating. In simple extra articular distal tibia fractures, closed reduction and fixation with external fixators can be used as definitive management. ${ }^{2}$

Open reduction and plating involves extensive soft tissue dissection and causes devascularization of underlying soft tissues and disruption of extraosseous blood supply of subcutaneous bone. ${ }^{2}$

In associated distal fibular fracture, some authors recommended to fix fibula but William et al recorded significantly more complications if fibula was fixed first in such cases with subsequent non-union of tibia. ${ }^{2}$ 
Minimally invasive locking plates have advantages of decreased soft tissue dissection and preservation of periosteal circulation but require indirect reduction techniques and is technically more demanding. ${ }^{7}$

Intramedullary nailing in distal tibia fractures acts as a good load sharing implant with minimal soft tissue dissection and spares periosteal blood supply. But there are documented complications of increased knee pain, fracture malalignment and decreased stability due to traditional locking systems and bone implant mismatch. ${ }^{7}$

Use of external fixators in compound distal tibia fractures as damage control orthopaedics followed by definitive internal fixation with plating or nailing to decrease soft tissue complications was a well established strategy. But a secondary surgical procedure causes physical, mental, economic and psychosocial burden on the patient. Thus making external fixation as the definitive management in such cases of non-compliance for second operation and extensive soft tissue loss. More attention is needed to watch out for complications like pin tract infections, loss of reduction and delayed or non-union. ${ }^{8}$

Ankle spanning external fixation can lead to possible complications like ankle joint stiffness, articular cartilage degeneration and osteomyelitis of calcaneal or metatarsal pin sites. But it gave a biomechanical advantage in fracture healing. Watson et al stated that ankle bridging monolateral frames provided sufficient fracture stability. The ankle spanning immobilizes ankle for initial soft tissue healing, neutralize compressive forces within the joint and also avoids the development of severe equinis deformity. The micromotion at fracture site leads to significant callus formation and fracture healing. ${ }^{9}$

The delta configuration aids in obtaining a congruent joint space with alignment of coronal and sagittal deformities with reduction maneuvers. ${ }^{10}$

\section{CONCLUSION}

Ankle spanning external fixation is a good modality of surgical management of extra articular compound distal tibia fractures as both temporary and definitive surgical fixation. It is an important part of damage control orthopaedics with simple surgical steps, least soft tissue dissection and decreased operative time. It preserves the surrounding soft tissue and periosteal circulation with enough time and space to manage associated compound open wounds. It can also be used as definitive fixation based on general condition and compliance of patient and soft tissue coverage.

Funding: No funding sources

Conflict of interest: None declared

Ethical approval: Not required

\section{REFERENCES}

1. Rathod J, Tailor H. Functional outcome of hybrid external fixator for fractures of metaphyseal distal tibia. Int J Orthopaed. 2019;5(1):205-11.

2. Ristiniemi J. External fixation of tibial pilon fractures and fracture healing. Acta Orthopaedica. 2007;78(326):2-34.

3. Lemsanni, M, Najeb Y, Chafik R, Madhar M, Elhaoury H. Outcome of complex tibial pilon fractures definitively treated with external fixator. Int J Res Orthopaed. 2020;6(6):1145-50.

4. Quinnan SM. Definitive management of distal tibia and simple plafond fractures with circular external fixation. J Orthopaed Trauma. 2016;30:26-32.

5. Babis GC, Kontovazenitis P, Evangelopoulos DS, Tsailas P, Nikolopoulos K, Soucacos PN. Distal tibial fractures treated with hybrid external fixation. Injury. 2010;41(3):253-8.

6. Prakash S, Rao V, Hardikar S, Pagdal S. External fixators in management of high energy distal third tibia fractures. Int J Orthopaed. 2019;5(2):684-7.

7. Hoenig M, Gao F, Kinder J, Zhang LQ, Collinge C, Merk BR. Extra-articular distal tibia fractures: a mechanical evaluation of 4 different treatment methods. J Orthopaed Trauma. 2010;24(1):30-5.

8. Hao ZC, Xia Y, Xia DM, Zhang YT, Xu SG. Treatment of open tibial diaphyseal fractures by external fixation combined with limited internal fixation versus simple external fixation: a retrospective cohort study. BMC Musculoskel Disord. 2019;20(1):1-8.

9. Antoci V, Voor MJ, Seligson D, Roberts CS. Biomechanics of external fixation of distal tibial extra-articular fractures: is spanning the ankle with a foot plate desirable? J Orthopaed Trauma. 2004;18(10):665-73.

10. Liskutin T, Bernstein M, Summers H, Lack W. Surgical technique: achieving anatomic alignment with temporizing, ankle-spanning external fixation. J Orthopaed Trauma. 2018;32:38-9.

Cite this article as: Mahajan NP, Kumar GSP, Patil TC, Bagimani PK. Fracture union in extra articular distal tibia fracture after definitive delta frame external fixation: a case report. Int J Res Orthop 2021;7:1035-8. 